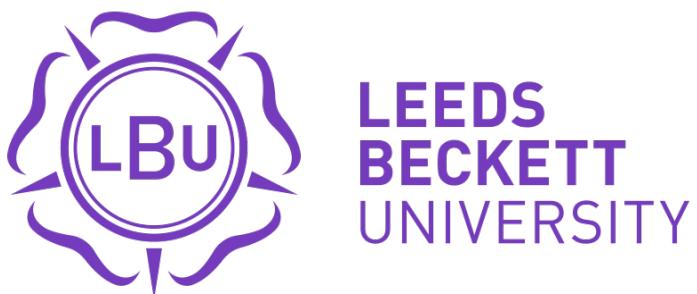

\section{Citation:}

Price, OJ and Hull, JH and Ansley, L (2014) Advances in the diagnosis of exercise-induced bronchoconstriction. Expert review of respiratory medicine, 8 (2). 209 - 220. ISSN 1747-6348 DOI: https://doi.org/10.1586/17476348.2014.890517

Link to Leeds Beckett Repository record:

https://eprints.leedsbeckett.ac.uk/id/eprint/2041/

Document Version:

Article (Updated Version)

The aim of the Leeds Beckett Repository is to provide open access to our research, as required by funder policies and permitted by publishers and copyright law.

The Leeds Beckett repository holds a wide range of publications, each of which has been checked for copyright and the relevant embargo period has been applied by the Research Services team.

We operate on a standard take-down policy. If you are the author or publisher of an output and you would like it removed from the repository, please contact us and we will investigate on a case-by-case basis.

Each thesis in the repository has been cleared where necessary by the author for third party copyright. If you would like a thesis to be removed from the repository or believe there is an issue with copyright, please contact us on openaccess@leedsbeckett.ac.uk and we will investigate on a case-by-case basis. 


\title{
ADVANCES IN THE DIAGNOSIS OF EXERCISE-INDUCED \\ BRONCHOCONSTRICTION
}

\author{
Oliver J. Price ${ }^{1}$, James H. Hull ${ }^{1,2}$, Les Ansley ${ }^{1}$
}

${ }^{1}$ Faculty of Health and Life Sciences, Northumbria University, Newcastle, United Kingdom (UK).

${ }^{2}$ Department of Respiratory Medicine, Royal Brompton Hospital, London, UK.

\section{Corresponding author:}

Dr Les Ansley

Faculty of Health and Life Sciences, Northumbria University,

Newcastle, NE1 8ST.

Tel: + 441912437773

Email: les.ansley@northumbria.ac.uk

\section{Abstract count: 118}

Word Count: 4607

Running title: Diagnosing exercise-induced bronchoconstriction. 


\section{ABSTRACT}

Exercise-induced bronchoconstriction (EIB) describes the post exercise phenomenon of acute airway narrowing in association with physical activity. A high prevalence of EIB is reported in both athletic and recreationally active populations. Without treatment, EIB has the potential to impact upon both health and performance. It is now acknowledged that clinical assessment alone is insufficient as a sole means of diagnosing airway dysfunction due to the poor predictive value of symptoms. Furthermore, a broad differential diagnosis has been established for EIB, prompting the requirement of objective evidence of airway narrowing to secure an accurate diagnosis. This article provides an appraisal of recent advances in available methodologies, with the principle aim of optimising diagnostic assessment, treatment and overall clinical care.

Key words: Airway dysfunction, airway-hyperresponsiveness, asthma, athletes, diagnosis, exercise-induced bronchoconstriction. 
"If from running, gymnastic exercises, or any other work, the breathing becomes difficult, it is called Asthma” Aretaeus (81-138 AD) [1].

\section{INTRODUCTION}

Respiratory symptoms in association with exercise are reported frequently in both elite athletic and recreationally active populations. However, differentiation between a 'normal' physiologically appropriate and 'abnormal' pathophysiological response of the cardiorespiratory system is complex, presenting a potential for misdiagnosis [2,3].

The most frequently encountered chronic medical condition in elite athletes is airway dysfunction [4]. Depending on the population studied and the diagnostic methodology employed, the estimated prevalence varies significantly. For instance, the prevalence in Olympians has been estimated at approximately $8 \%$ [4], whereas in high risk populations (i.e. swimmers and cold-air athletes) the estimate is much greater (25-75\%) [5-7]. In contrast, the prevalence of airway dysfunction in recreationally active individuals has recently been identified at $>13 \%$ [8]. Consequently, diagnostic accuracy in clinical practice is of fundamental importance to ensure the appropriate application of effective treatment.

Airway dysfunction is a term used to describe the entities of exercise-induced bronchoconstriction (EIB), exercise-induced asthma (EIA), airway hyper-responsiveness (AHR) and/or asthma [7]. Whilst often used interchangeably with EIA, EIB is the preferred terminology given exercise triggers bronchoconstriction rather than inducing the clinical syndrome of asthma [9]. Specifically, EIB describes the post exercise phenomenon of acute airway narrowing in association with physical activity $[5,10]$. Clinical characteristics of EIB often include dyspnoea, increased perceived effort of breathing, chest tightness, wheezing, excessive sputum production and/or cough. In addition, individuals with the aforementioned 
symptoms may also report a reduction in physical performance and/or earlier onset of fatigue following a strenuous bout of exercise [3].

The diagnosis of EIB in athletes has presented difficulties in the past, predominately because baseline spirometry possesses poor predictive value [11] and primary care physicians rely heavily on self-report respiratory symptoms. However, it is now established that a symptombased approach to diagnosis is imprecise as symptoms correlate poorly with objective evidence of airway narrowing [2,12]. As such, it is now recognised that an accurate diagnosis of EIB should be established through changes in lung function following a provocative stimulus to the distal airways, rather than on the basis of clinical features alone [10]. Whilst the International Olympic Committee-Medical Commission (IOC-MC) favour eucapnic voluntary hyperpnoea $(\mathrm{EVH})$ as the 'gold-standard' bronchoprovocation challenge for EIB in athletes [13], a number of supplementary tests are currently available, with developments in diagnostic methods an active area of research.

The aim of this review was therefore to appraise recent developments in available diagnostic methodology for EIB in athletes, with the purpose of optimising diagnostic accuracy, treatment and clinical care in both athletic and recreationally active populations. Throughout the evidence presented is based on a narrative non-systematic review. Publications in peerreviewed literature until November 2013 were reviewed using the following terms 'exerciseinduced asthma or bronchoconstriction', 'airway-hyperresponsiveness', 'asthma', 'airway dysfunction' and 'diagnosis', in combination with 'athletes'. 


\section{PATHOGENESIS OF EIB}

The last 50 years has consisted of considerable debate surrounding the mechanistic development of EIB [14]. Whilst a wealth of research has been conducted [15-18] the pathogenesis of EIB remains complex and incompletely understood.

During intense exercise, ventilation rates may exceed $150 \mathrm{~L} / \mathrm{min}$ resulting in a shift in resting breathing pattern from predominately nasal to combined oral and nasal airflow [19]. Consequently, the distal airways are exposed to an increase in unconditioned air and potential interaction with sport-specific environmental pollutants such as airborne allergens and noxious particles $[20,21]$. The acute development of EIB is thought to precipitate EIB by inducing osmotic changes at the distal airway surface whereby desiccation of the airway epithelium drives a local osmotic stimulus resulting in cell shrinkage, pro-inflammatory mediator release and a shift in cellular ion concentration [15,17,22]. Specifically, evidence has highlighted the release of arachidonic acid metabolites such as cysteinyl leukotrienes and prostaglandin $\mathrm{D}_{2}$ from mast cells and eosinophils into the airways [23-25]. It has been proposed that these respective eicosanoids act as principle mediators resulting in sensory nerve activation, smooth muscle contraction [23] and mucus release into the airway lumen [26]. See reference [18] for a recent detailed review.

More recently, a shift in focus towards airway injury has occurred, with recent findings indicating that acute exercise hyperpnoea transiently disrupts the airway epithelium [27]. In the chronic setting, repeated, sustained periods of exercise hyperpnoea have been associated with changes in the contractile properties of smooth muscle analogous to a pathological response to injury or insult $[28,29]$. To date, it is generally accepted that a causal relationship exists between repeated exercise hyperpnoea in noxious environments and injury-repair cycling of the airway epithelium. Over time this stimulus appears to result in an increase in 
endobronchial debris, pro-inflammatory cells, cellular inflammatory mediators, airway remodelling and overall heightened sensitivity to mediators of bronchoconstriction $[7,16,29]$ (Figure 1).

Furthering our knowledge of the mechanisms underlying the pathogenesis of EIB will provide insight into the optimum bronchoprovocation challenges to employ and overall aid diagnostic accuracy.

\section{RESPIRATORY SYMPTOMS}

It is commonplace for primary care physicians to regularly encounter patients reporting dyspnoea in association with exercise. Indeed, UK physicians report an encounter with symptomatic patients at a rate of approximately once per month [30]. Furthermore, a study of 700 athletes found that almost $25 \%$ report regular symptoms indicative of airway dysfunction [31]. Due to the distinguishing characteristics of EIB, physicians often rely solely on selfreport symptoms alone to inform diagnosis. Whilst this may seem intuitive, a wealth of literature now opposes this practice, highlighting the fact that symptoms correlate poorly with objective evidence of airway narrowing [2], possessing the (in)accuracy of a coin toss [12]. For example, studies in athletes implementing a symptom based criteria as the principle means of diagnosis generally state prevalence below $20 \%$. In contrast when objective bronchoprovocation challenges are employed the prevalence tends to be above $20 \%[32,33]$. Overall, symptoms that are often associated with vigorous exercise are neither sensitive nor specific for identifying patients with EIB [34,35].

Discrepancies in accurate diagnosis and estimated prevalence occur further when considering a significant proportion of individuals with airway dysfunction have no previous history of symptoms [36,37]. Recent findings from Molphy and colleagues highlight this concern 
whereby $>13 \%$ of asymptomatic recreationally trained individuals presented with objective evidence of airway narrowing.

The explanation for the dissociation between symptoms and objective evidence is likely multifactorial. A principle concern for physicians encountering patients with exercise-related respiratory symptoms is the vast differential diagnosis associated with EIB. For instance, cardiac dysfunction, poor physical conditioning or other respiratory disease present symptoms during maximal exercise and improve with recovery [3,38]. In addition, accuracy of patient self-report is generally non-specific [31] and personality trait, perception of symptoms, and expectation of performance likely influence the accuracy of a symptom based diagnosis.

\section{DIAGNOSTIC IMPLICATIONS}

The implications of misdiagnosis can be considered two-fold; firstly and most importantly in terms of airway health and secondly regarding athletic performance.

The impact of airway dysfunction on health spans a broad spectrum, from quality of life to morbidity (e.g. exacerbations) and mortality. Whilst longitudinal data suggests no long-term consequences of airway dysfunction in former athletes [39] evidence suggests that a high proportion of asthma-related deaths occur in elite competitive athletes in association with a sporting event $[40,41]$. Furthermore, misdiagnosis of a condition and failing to implement appropriate treatment presents a potential for deterioration. In contrast, when prescribed unnecessarily, medication has been associated with degenerative changes in lung function and the development of tachyphlaxis following chronic use of beta-2-agonists $[42,43]$.

Specific to athletic performance, 1993 saw the IOC-MC introduce restrictions in the use of asthma medications at international level of competition. This year the World Anti-Doping 
Agency (WADA) has implemented further changes in their policy for therapeutic use exemption (TUE), the process whereby an athlete may use an otherwise prohibited substance to treat a medical condition [44]. It is currently acknowledged that clinical assessment is insufficient as a sole means of diagnosing airway dysfunction due to the poor predictive value of symptoms and the broad differential diagnosis [45]. Thus, the current policy requires submission of objective evidence of airway dysfunction following reversibility or bronchoprovocation testing before medication can be deemed acceptable.

\section{DIAGNOSIS OF EIB}

\section{Pre-test instructions}

In order to standardise results and limit the variability in response to bronchoprovocation challenges, patients must adhere to a strict criteria prior to testing (Table 1). For surveillance purposes in athletes, testing should be performed at the same time of day to minimise diurnal variation in airway tone. Furthermore, athletes participating in clinical trials should aim to maintain a strict training load between visits.

\section{Diagnostic guidelines}

The diagnosis of EIB is determined by changes in lung function post exercise. Serial lung function measurements post exercise or surrogate challenges are used to determine the presence of EIB and quantify the severity of the disorder [10]. The American Thoracic Society/European Respiratory Society (ATS/ERS) guidelines currently recommend at least two reproducible $\mathrm{FEV}_{1}$ manoeuvres obtained serially following provocation, with the highest acceptable value recorded at each interval $[46,47]$. $\mathrm{FEV}_{1}$ is usually measured at 3,5,10,15 and 30 minutes post exercise, with a fall in $\mathrm{FEV}_{1} \geq 10 \%$ at two consecutive time points indicative 
of a positive diagnosis [48]. The severity of EIB can be classified as mild, moderate or severe depending on the percent fall in $\mathrm{FEV}_{1}$ and current prescribed medication Table 2. [10].

Diagnostic methodology for EIB can be divided into two respective categories; direct and indirect bronchoprovocation challenge tests. Direct challenges act directly on specific airway smooth muscle receptors to induce constriction independent of airway inflammation $[49,50]$. In contrast, indirect challenges are thought to cause inflammatory cells to release endogenous mediators such as leukotrienes, prostaglandins and histamine that provoke airway smooth muscle constriction $[46,50,51]$.

At present the International Olympic Committee (IOC-MC) currently accept a number of diagnostic challenges as objective evidence of asthma and EIB. These include bronchodilator reversibility testing, eucapnic voluntary hyperpnoea, methacholine challenge testing, laboratory and field exercise testing and saline or dry powder mannitol challenges [44,52]. A secure diagnosis then depends on confirmatory investigation (proposed assessment algorithm is presented in Figure 2). These methods will form the basis of this review; however, a comprehensive description for each of the protocols, procedures and techniques employed in clinical practice is beyond the scope of this article. For these the reader is referred to the relevant ATS/ERS guidelines. In addition, a systematic appraisal of sensitivity and specificity previously formulated by Dryden and co-workers [53] using the Grading of Recommendations, Assessment, Development and Evaluation (GRADE) approach is presented for each respective bronchoprovocation challenge (Table 3). 


\section{DIRECT BRONCHOPROVOCATION CHALLENGES}

\section{Methacholine vs. Histamine inhalation challenge}

Direct bronchoprovocation challenges such as the methacholine and histamine inhalation challenge are the most commonly performed diagnostic tests for AHR [49,54]. Whilst methacholine and histamine induce bronchoconstriction at almost equivalent concentrations $[55,56]$, methacholine is more commonly employed due to a number of systemic side effects associated with histamine including headaches and flushing [47]. In addition, evidence suggests that AHR measurements may have greater reproducibility when employing a methacholine challenge [57-59]. To date, methacholine is the only direct bronchoprovocation challenge recognised by the IOC-MC as appropriate evidence to permit use of inhaled medication to treat airway dysfunction in athletes [13].

\section{Methacholine inhalation challenge}

Methacholine inhalation challenge is considered a direct challenge as it acts on smooth muscle acetylcholine receptors, causing contraction and airway narrowing [60]. The dosing protocol of a methacholine challenge consists of either a 2-minute tidal breathing or dosimeter method. Specifically, the two minute-tidal breathing method consists of the inhalation of aerosol from a jet nebulizer, operated while continually calibrated to an output of $0.13 \mathrm{ml} / \mathrm{min}$. In contrast, the dosimeter method requires an inhalation of aerosol $(9 \mu \mathrm{L}$ per actuation) with five deep inspiratory capacity inhalations to total lung capacity, followed by a 5 second breath hold after each inhalation [49]. Other than the inhalation procedure, the recommendations for the respective tests are the same [61]. Administration of a baseline control saline diluent begins the test, followed by doubling concentrations of the provocative agent from $0.03 \mathrm{mg} / \mathrm{mL}$ to $16 \mathrm{mg} / \mathrm{mL}$ or $32 \mathrm{mg} / \mathrm{mL}$. Intervals of 5 minutes are required 
between inhalations, with single measures of $\mathrm{FEV}_{1}$ performed at $30 \mathrm{~s}$ and $90 \mathrm{~s}$ post inhalation [49]. The percentage fall in $\mathrm{FEV}_{1}$ following the inhalation of methacholine can be calculated based on baseline (saline diluent) $\mathrm{FEV}_{1}$. The test is complete when the highest concentration of methacholine has been administered, or deemed positive when a $20 \%$ fall in $\mathrm{FEV}_{1}$ has occurred ( $\mathrm{PC}_{20}$, provocative concentration causing a fall in $20 \%$ in $\left.\mathrm{FEV}_{1}\right)$. It was previously thought that although the volume of aerosol differed between the two methods, the results were comparable [62]. However, and of concern, recent evidence has accumulated to suggest the tidal-breathing method produces a greater response (lower $\mathrm{PC}_{20}$ ). This is likely multifactorial; firstly, the dose administered is significantly higher with the tidal breathing method. Secondly, maximal inspiratory efforts and subsequent breath-holds likely result in a degree of bronchodilation in patients with mild AHR [63,64]. Of note, the methods are much more comparable in patients with moderate or severe AHR $[61,65]$.

Airway hyper-responsiveness to pharmacologic agents such as methacholine has been shown to differ from hyperresponsiveness to exercise or osmotic agents [47]. Furthermore, unlike exercise challenges, methacholine does not infer the presence of inflammatory cells or their mediators [51]. Therefore, whilst the arbitrary cut-off points for methacholine results in good specificity in diagnosing the clinical syndrome of asthma [49], when considered from an EIB perspective, sensitivity and specificity appears inconsistent and imprecise respectively [53].

In support of this concept, Holzer and colleagues have previously identified that methacholine had a negative predictive value of merely $61 \%$ and a sensitivity of $36 \%$ for identifying EIB in elite athletes in comparison to EVH [66]. A recent systematic appraisal of evidence concluded that methacholine is not a valid test to diagnose EIB [53]. Furthermore, a positive methacholine test should not be used to infer EIB, and likewise a negative result should not exclude EIB [47]. 


\section{INDIRECT BRONCHOPROVOCATION CHALLENGES}

\section{Exercise challenge tests}

As exercise is a natural provocative stimulus to induce bronchoconstriction in susceptible individuals, it seems logical to implement exercise as a diagnostic test. As such, exercise testing was the first indirect bronchoprovocation challenge to be standardised for the diagnosis of airway dysfunction [67]. As the mode, duration and intensity of exercise and the temperature and water content of the inspired air influence the dehydration/heat transfer of the airways [17] both laboratory and sport-specific field tests have been developed [68].

The reproducibility of exercise testing has previously been established by Anderson and coworkers [69], with agreement of $76.1 \%$ between test results. However, the authors concluded that when using exercise to exclude or diagnose EIB, prescribe treatment or implement during clinical trials, performing two tests would be advantageous.

The recommended protocol for the identification of EIB when implementing an exercise challenge consists of a rapid increase in exercise intensity over approximately $2-4$ minutes to achieve a sustained, high level of ventilation. Throughout the challenge, dry, medical grade air $\left(<10 \mathrm{mg} \mathrm{H}_{2} \mathrm{O} / \mathrm{L}\right.$ ) should be inhaled with a nose clip in place (optimising distal airway exposer) while running or cycling at a load to sufficiently raise the heart rate to $80-90 \%$ of predicted maximum (predicted maximum heart rate: 220 (bpm) - age (yr)) [10]. This level of exercise should subsequently be maintained for an additional 4-6 minutes, resulting in achieving and maintaining $\mathrm{V}_{\mathrm{E}}$ at approximately $85 \%$ maximal voluntary ventilation. Of note, when screening highly conditioned or elite level athletes an intensity of approximately $95 \%$ $\mathrm{HR}_{\text {peak }}$ or $\mathrm{VO}_{2 \max }$ test to volitional exhaustion is recommended, thus ensuring a sufficient provocative stimulus [50]. 
Lung function should be assessed at baseline and 3, 5, 10, 15 and 30 minutes post challenge in accordance with ATS/ERS guidelines $[38,46,47]$. The response to an exercise challenge is considered positive when there is a fall in $\mathrm{FEV}_{1}$ of $\geq 10 \%$ [48].

\section{Laboratory vs. Field-based challenges}

Laboratory and field-based exercise challenge tests have been identified to have high specificity however possess only moderate sensitivity for EIB [70]. For instance, the laboratory challenge test is often performed on a treadmill or cycle ergometer and is limited by an inability to achieve the desired workload and thus ventilation rate to induce EIB in highly conditioned or elite athletes [71]. In addition, running and cycling possess little relevance to the athlete describing symptoms during swimming, football, skiing, skating etc. [46]. Finally, the high water content of ambient inspired air limits the drying and desiccation of the distal airways to induce bronchoconstriction in susceptible individuals [68].

Field-based challenges where athletes perform a challenge using their primary mode of exercise (i.e. sporting event), are limited by an inability to standardise both the cardiovascular workload and key environmental components such as temperature and humidity of inspired air [71]. Overall, sensitivity and specificity limitations associated with laboratory and fieldbased exercise challenges has resulted in the development of a number of indirect surrogate challenges to overcome these problems $[72,73]$.

\section{Eucapnic voluntary hyperpnoea}

Eucapnic voluntary hyperpnoea is a bronchoprovocation challenge based on the premise that increased ventilation rate mimicking high intensity exercise desiccates the distal airways, inducing bronchoconstriction in susceptible individuals [50]. Indeed the symptoms indicative 
of EIB (cough, wheeze, dyspnoea, chest tightness etc.) are often provoked during an EVH challenge [71].

The standardised protocol consists of performing hyperpnoea by inhaling a dry gas mixture containing $4.9-5 \%$ carbon dioxide, $21 \%$ oxygen and nitrogen as the balance. The test is performed in ambient conditions at room temperature for a 6-minute period. To minimise the likelihood of a false negative test, a ventilation rate equivalent to 30 times baseline $\mathrm{FEV}_{1}$ is required [74,75]. As many untrained individuals may fail to achieve this value, 21 times baseline $\mathrm{FEV}_{1}$ is the minimum threshold to validate the test $[75,76]$. As with exercise, a $\geq 10 \%$ fall in $\mathrm{FEV}_{1}$ from the pre-challenge value following $\mathrm{EVH}$ is consistent with a diagnosis of EIB [77].

Eucapnic voluntary hyperpnoea has previously been reported as highly specific for the diagnosis of asthma and EIB. Indeed the accuracy of diagnosis for active asthma has been shown to be $90 \%$ when implementing a $10 \%$ fall in $\mathrm{FEV}_{1}$ and $100 \%$ when extending the cutoff value to $15 \%$ fall in $\mathrm{FEV}_{1}$ [77]. However, a more recent systematic appraisal of evidence [53] suggested that both specificity and sensitivity of an EVH challenge were heterogeneous and inconsistent when applied specifically to EIB.

Although Stadelmann and colleagues have previously observed high repeatability for EVH, the time between tests was not defined and evidence of training load maintenance was not reported [78]. Accordingly, the short and long-term repeatability of this methodology has yet to be fully established.

In addition, due to the high potency of EVH, a 5-10\% fall in $\mathrm{FEV}_{1}$ may well be considered a normal airway response. Consequently, debate currently surrounds the treatment of asymptomatic athletes with a $10 \%$ fall in $\mathrm{FEV}_{1}$. Indeed it remains the opinion of many 
European researchers studying EIB in athletes (variety of personal communications) that a cut-off $\geq 15 \%$ fall in $\mathrm{FEV}_{1}$ should be employed to determine a positive EIB diagnosis. Furthermore, when a decline in lung function 'borderline' of diagnostic cut-off points is observed, further testing should be performed.

Nonetheless, to date, EVH is recommended as the 'gold-standard' challenge by the IOC-MC as the most reliable test for the identification of EIB in athletes [13]. However, in athletes with severe or poorly controlled asthma, it would be advised to conduct a dry powder mannitol or hyperosmolar aerosol test. As these tests are progressive in nature, they are therefore unlikely to cause severe bronchoconstriction which may occur following exercise or EVH.

\section{Dry powder mannitol}

Inhaling dry powder mannitol increases the osmolarity of the airway surface liquid causing the release of endogenous inflammatory mediators through the same indirect pathway as exercise and EVH $[79,80]$. The protocol for mannitol consists of inhaling increasing doses of mannitol delivered via a capsule-based dry powder inhaler [60]. $\mathrm{FEV}_{1}$ is measured in duplicate 60 seconds following each administered dose of mannitol $(0,5,10,20,40,80,160$, $160,160 \mathrm{mg})$. The maximum time for the test should be no longer than 35 minutes for the full $635 \mathrm{mg}$ dose [60]. A positive test result is a $15 \%$ fall in $\mathrm{FEV}_{1}$ in comparison to pre-challenge $\mathrm{FEV}_{1}[60]$. Following a systematic appraisal of current evidence from Dryden and co-workers [53], the sensitivity and specificity of mannitol has been estimated between 58 to $96 \%$ and 65 to $78 \%$ respectively. The authors concluded that whilst such estimates are reasonably consistent, they lack precision, overall questioning the reliability of dry powder mannitol as a diagnostic test for EIB. 


\section{Hyperosmolar aerosol}

Similar to mannitol, the hyperosmolar (4.5\%) inhaled saline test was developed as a surrogate to exercise based on the principle osmotic stimulus of evaporative water loss during exercise [81]. The recommended protocol for inhaled saline consists of the patient inhaling the saline via tidal breathing from a large volume ultrasonic nebuliser for a period of 30 seconds. FEV 1 is measured in duplicate 60 seconds post exposure. If the reduction is $<10 \%$ of pre-challenge $\mathrm{FEV}_{1}$ then the exposure to the saline is doubled (e.g. $30 \mathrm{sec}, 60 \mathrm{sec}, 2 \mathrm{~min}, 4 \mathrm{~min}, 8 \mathrm{~min}$ ). If the reduction in $\mathrm{FEV}_{1}$ is $\geq 10 \%$ of the pre-challenge, the same dose is repeated. The test is terminated when the $\mathrm{FEV}_{1}$ falls by $15 \%$ or when the maximum dose of 23 grams has been administered in 15.5 minutes [82]. The diagnostic sensitivity and specificity of $\mathrm{PD}_{15}$ to $4.5 \%$ saline when based on $\geq 10 \% \mathrm{FEV}_{1}$ fall was $53.9 \%$ and $84.7 \%$ respectively in a cohort of children $(\mathrm{n}=348)[83]$.

\section{ADDITIONAL DIAGNOSTIC TESTS}

Due to the difficulties obtaining an accurate diagnosis of airway dysfunction through specific bronchoprovocation challenges, a number of supplementary measurements have been developed and employed.

\section{Atopic status}

As self-report symptoms only provide a supportive role to inform diagnosis, implementing screening questionnaires such as the Allergy Questionnaire for Athletes (AQUA) [84] may be valuable in providing a structured and objective patient clinical history. Furthermore, objective tests such as skin prick testing are often employed in clinical practice to determine atopic disposition to common airborne allergens. Determining atopic status is important as 
the likelihood of an athlete having increased bronchial responsiveness increases to the number of positive skin responses [85].

\section{Impulse oscillometry}

Impulse oscillometry (IOS) provides an alternative method of measuring lung mechanics in respiratory disease states. Impulse oscillometry consists of random pressure pulses of $5 \mathrm{~Hz}$ to $35 \mathrm{~Hz}$ (produced by a small loudspeaker in connection with a pneumotach) applied during tidal breathing. In contrast to spirometry, IOS is a non-effort dependent test, and therefore has application in patients who are unable to deliver a forced expiration (i.e. elderly or paediatric populations). Therefore, IOS is advantageous in that results cannot be manipulated by the patient [86], nor does it induce respiratory fatigue [87]. In addition, IOS has previously been identified to correlate with both $\mathrm{FEV}_{1}[88,89]$ and airway resistance $[90,91]$ as determined by spirometry and body plethysmography respectively.

Specific to EIB, IOS has been shown to be an acceptable measure to supplement spirometry following EVH [92]. In support of these findings, Evans and colleagues observed strong correlations between spirometry and IOS variables. Furthermore, IOS possessed greater sensitivity compared to spirometry when detecting change in airway function following EVH and exercise $[93,94]$. Consequently, IOS may provide a potential adjunct to reliable and accurate diagnosis of EIB. However the utility and clinical relevance of IOS in respiratory medicine is widely disputed and the repeatability in this setting has yet to be established.

\section{Inflammatory biomarkers}

Inflammatory biomarkers such as fractional exhaled nitric oxide ( $\mathrm{FE}_{\mathrm{NO}}$ ), exhaled breath temperature $(\mathrm{EBT})$ and exhaled breath condensate $(\mathrm{EBC})$ provide a potential diagnostic role 
including predicting and monitoring airway dysfunction [95-97] (see reference [98] for a detailed overview).

Fractional exhaled nitric oxide is regarded as an indirect marker for up-regulation of airway inflammation [99]. A recent systematic review by Feitosa and co-workers [100], established that overall FENO is a reliable test to determine the presence of EIB. The authors concluded that a strong possibility of EIB occurred when a cut-off point is set at $>28 \mathrm{ppb}$ for children under 8 years old and $>12 \mathrm{ppb}$ for adults, and ruled out with a cut-off point of $<20$ for children between 5-16 years old and $<7 \mathrm{ppb}$ for adults.

Exhaled breath condensate measures a number of compounds including biomarkers of inflammation (e.g. leukotrienes, prostaglandins, cytokines, adenosine, chemokines and interleukins) and oxidative stress (e.g. 8-isoprostanes, $\mathrm{H}_{2} \mathrm{O}_{2}$ ) [98]. In addition to diagnosis, the use of EBC has precedence in monitoring the effectiveness of treatment and also understanding the pathogenesis of EIB.

Exhaled breath temperature may also provide insight into securing a diagnosis of EIB. A recent study by Peroni and colleagues [96] demonstrated a mean increase in tidal EBT of approximately $0.4^{\circ} \mathrm{C}$ from baseline following a 6-minute exercise challenge in asthmatic children. The increase in EBT correlated with the maximum fall in $\mathrm{FEV}_{1}$ supporting the hypothesis that EBT is a composite biomarker that may be used to monitor aspects of airway dysfunction i.e. airway remodelling and inflammation.

Implementing inflammatory biomarker analysis in clinical practice provides additional evidence to ensure secure diagnosis and accurate treatment. To date, FENO is the gold standard gas for assessing airway response to exercise hyperpnoea; however EBT and EBC likely provide additional beneficial information. Overall, the simplicity, cost, timeframe and 
non-invasive nature make employing these methodologies attractive to daily clinical practice. In addition, the application of biomarker analysis would be of particular relevance for surveillance purposes in athletic populations susceptible to the development of EIB (i.e. swimmers and cold-air athletes).

\section{DIFFERENTIAL DIAGNOSIS}

A broad differential diagnosis for EIB exists in elite athletes including anaemia, physical deconditioning, cardiac and other pulmonary diseases [101] (see reference [9] for a detailed overview). Whilst a thorough clinical history and physical examination in conjunction with specific lung function, bronchoprovocation challenges, and cardio-pulmonary exercise testing (CPET) can with certainty exclude the majority of respiratory and cardiac related disorders, some conditions will require further investigation and specialist tests [9] (Figure 2). A highly prevalent differential or mimic of EIB in young athletes is exercise-induced laryngeal obstruction (EILO) - 'an abnormal laryngeal response to exercise' in which clinical features such as dyspnoea and wheezing are generated from the upper airways [9,101,102]. Accordingly, symptomatic athletes with a negative bronchoprovocation challenge may require nasendoscopic evaluation of their laryngeal movement - recorded continuously during exercise [102]. A recent study by Walsted and colleagues observed that from a cohort of 88 athletes, approximately one third had evidence of EILO as an explanation for their exercise-related respiratory symptoms [102]. However, it is important to highlight that although EIB and EILO are separate clinical entities, they may co-exist in the same patient [103]. When considering differentiation is particularly difficult when symptoms are employed as the primary means of diagnosis, implementing objective testing in clinical practice is of paramount importance. 


\section{SUMMARY}

In conclusion, exercise-induced bronchoconstriction presents with non-specific symptoms that make diagnosis based on medical history and physical examination both challenging and unreliable. Therefore, objective testing is often required and strongly recommended to confirm or refute a diagnosis of EIB. In addition, the importance of careful consideration for potential differential diagnosis should not be overlooked.

The appraisal of current literature supports the use of indirect bronchoprovocation challenges, with EVH currently deemed as the optimal challenge by the IOC-MC to secure a diagnosis of EIB in athletes. Whilst employing an indirect bronchoprovocation challenge is advised as the first course of action, caution is recommended when diagnosing based on a solitary screening and a stringent cut-off value of $\geq 10 \%$ fall in $\mathrm{FEV}_{1}$. Indeed borderline cases may merit followup testing to ensure a correct diagnosis has been established prior to initiating treatment. Furthermore, it is important to highlight that regular surveillance of lung function following a diagnosis should be implemented (i.e. monitor changes in inflammatory biomarkers) in order to effectively modify treatment and optimise clinical care. 


\section{TABLE FOOTNOTES}

Table 1. Pre-test patient instructions.

Table 2. Severity of EIB based on decline in $\mathrm{FEV}_{1}$ following a bronchoprovocation challenge.

Definition of abbreviations: EIB; exercise-induced bronchoconstriction; $\mathbf{F E V}$; forced expiratory volume in one second.

Table 3. Summary of sensitivity and specificity for the bronchoprovocation challenges currently accepted by the IOC-MC.

Definition of abbreviations: GRADE; Grading of Recommendations Assessment, Development and Evaluation; EIB; exercise-induced bronchoconstriction; $\mathbf{F E V}$; forced expiratory volume in one second. 
Table 1.

\section{Confounding factors}

Clothing

Smoking

Exercise

Diet

Medication

Other medical conditions

\section{Patient requirements}

- Avoid wearing tight, restrictive clothing when performing lung function tests.

- Do not smoke for at least 1 hour prior.

- Avoid vigorous exercise on the day of testing.

- Avoid eating 2 hours prior to testing.

- Avoid caffeine on the day of testing.

- Do not consume alcohol on the day of testing.

- Abstain from anti-histamine medication 24 hours prior to testing.

- Abstain from short-acting beta2 agonists (e.g. salbutamol) 24 hours prior to testing.

- Abstain from inhaled corticosteroids 72 hours prior to testing.

- Do not perform lung function testing on patients who have any of the following conditions:

- Recent myocardial infarction/unstable angina

- Recent abdominal/thoracic/eye surgery

- Pneumothorax

- Haemoptysis of unknown cause 
Table 2.

\begin{tabular}{lc} 
Classification of EIB severity & Percent decrease in FEV $\mathbf{1}$ \\
\hline Normal airway response & $0 \%-<10 \%$ \\
Mild & $\geq 10 \%-<25 \%$ \\
Moderate & $\geq 25 \%-<50 \%$ \\
Severe (steroid-naïve patients) & $\geq 50 \%$ \\
Severe (steroid-treated patients) & $\geq 30 \%$ \\
\hline
\end{tabular}


Table 3.

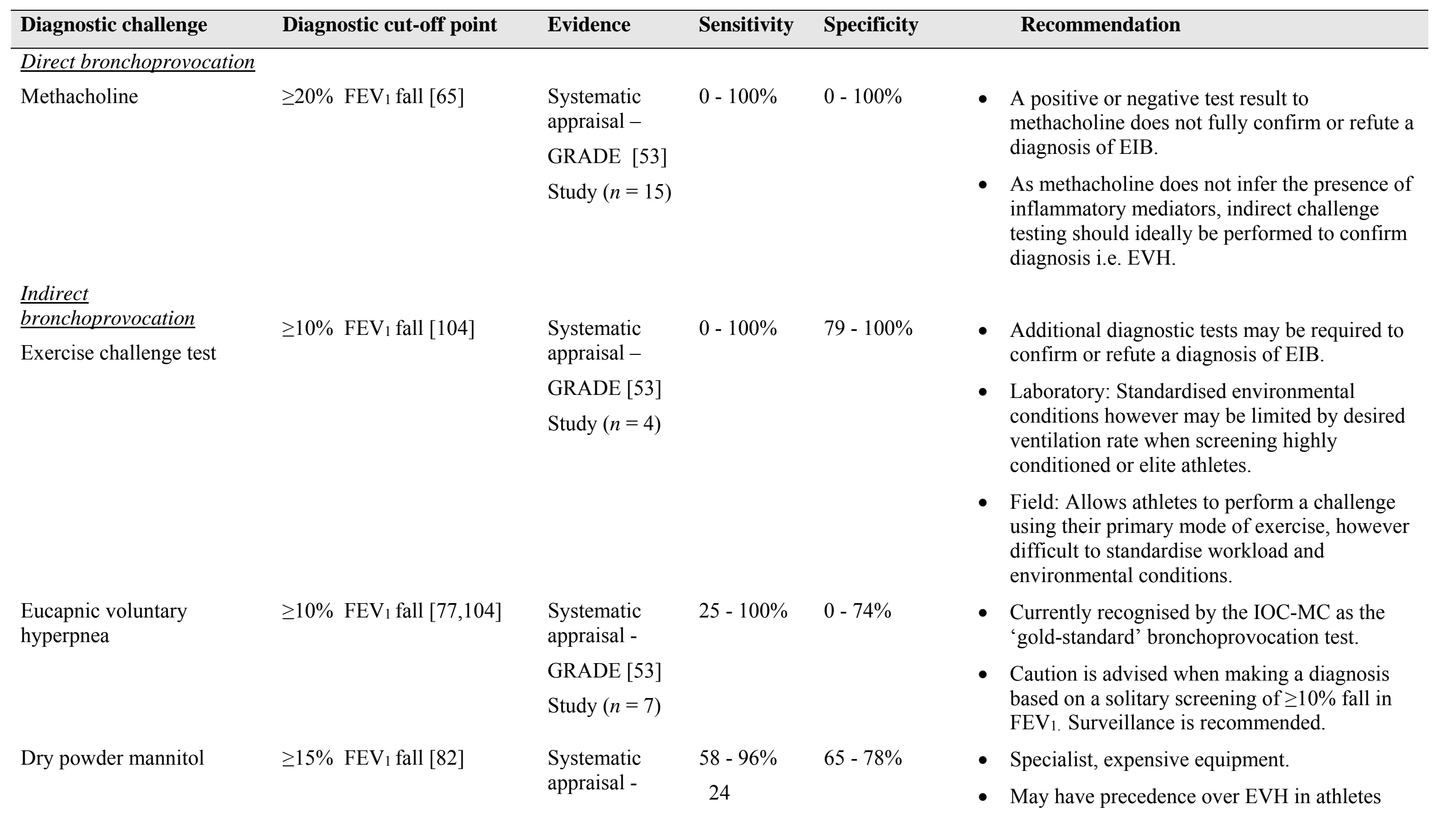




\section{GRADE [53]}

Study $(n=3)$

Hypertonic saline 4.5\% $\geq 15 \% \mathrm{FEV}_{1}$ fall [82]

\author{
Epidemiologic $\quad 53.9 \% \quad 84.7 \%$ \\ survey [83] \\ Study $(n=1)$
}

exercising in warm, humid environmental conditions.

- Further research required to understand the utility of mannitol as a diagnostic challenge for EIB in athletes.

- Advised when screening athletes with severe or poorly controlled asthma.

- Specialist, expensive equipment.

- Further research required to understand the utility of hypertonic saline as a diagnostic challenge for EIB in athletes.

- Advised when screening athletes with severe or poorly controlled asthma. 


\section{FIGURE LEGENDS}

Figure 1. Impact of exercise hyperpnoea on airway health in susceptible athletes. Reproduced with permission from Price and Hull [105].

Figure 2. Approach to the diagnostic assessment and management of asthma in elite athletes with suspected airway dysfunction. Reproduced with permission from Hull et al. [101].

***Permission required before figures are published in Expert Reviews*** 


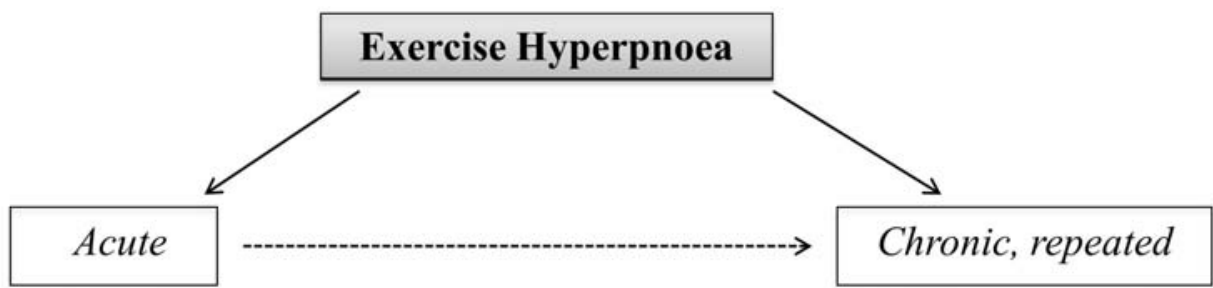

Dehydration of the airway surface liquid (ASL) $\longrightarrow$ Airway

$\downarrow$

Increase osmolarity of ASL

$\downarrow$

Water moves from cells to restore ASL

$\downarrow$

Cells shrinkage

Pro-inflammatory mediator release

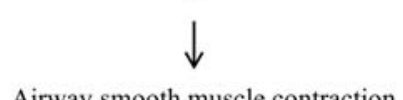

Airway smooth muscle contraction cooling

Airway injury (repeated/prolonged exposure)
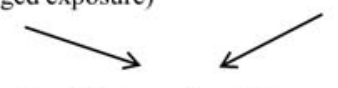

$\uparrow$ Injury-repair cycling

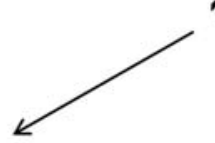

Epithelial cell activation and shedding

Pro-inflammatory milieu

Smooth muscle and mucous gland proliferation<smiles>CCC</smiles>

Airway epithelial damage

Loss of protective airway barrier

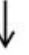

$\uparrow$ Propensity to airway narrowing

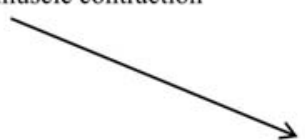

hyperemia

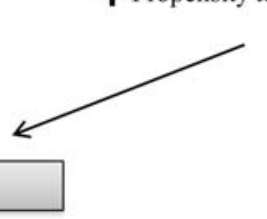

Exercise-induced bronchoconstriction

\section{Figure 1.}




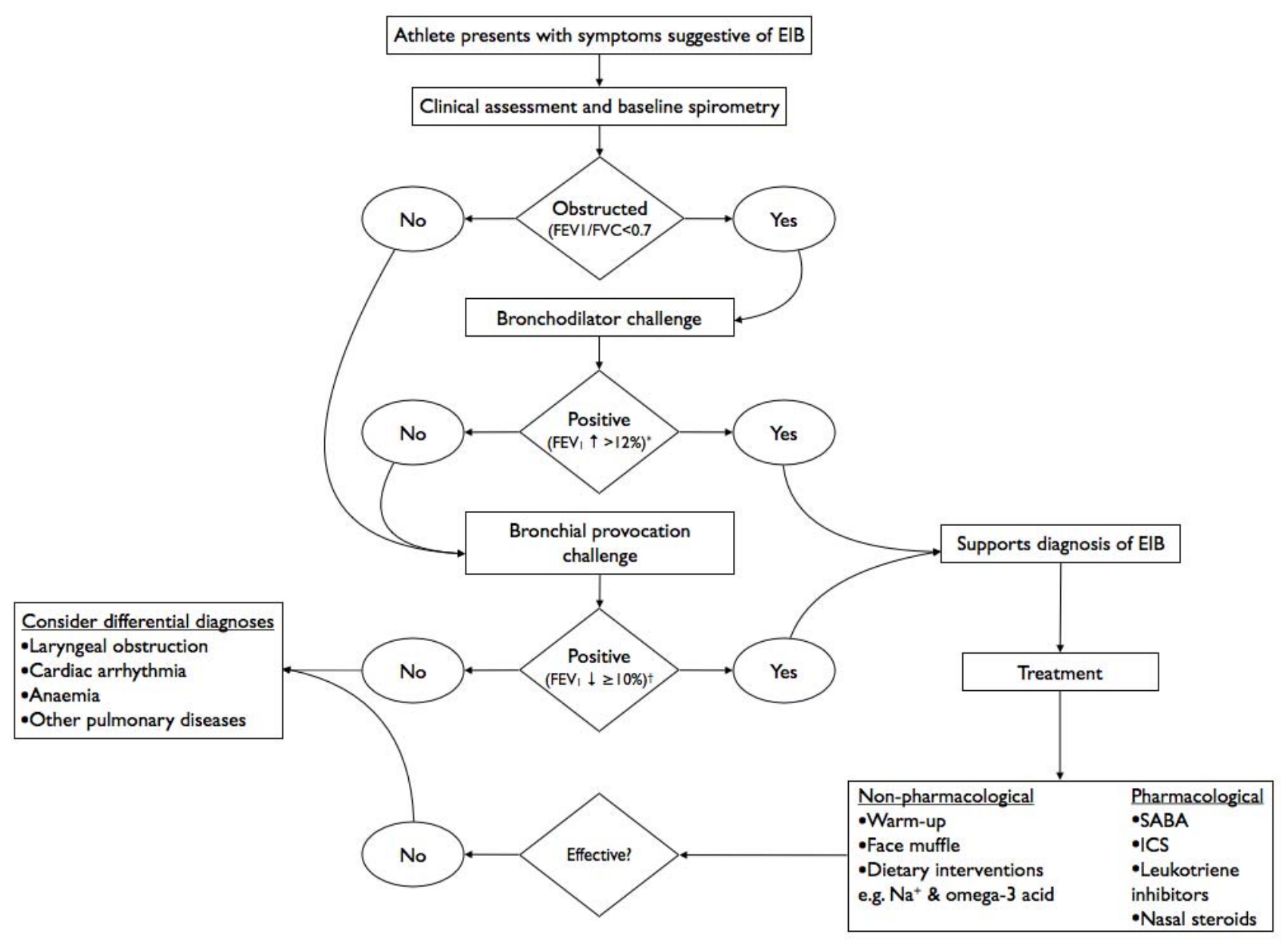

Figure 2. 


\section{ACKNOWLEDGEMENTS}

Nil

FUNDING STATEMENT

Nil relevant

\section{COMPETING INTERESTS}

The authors have no real or perceived conflict of interest in respect of this manuscript.

\section{CONTRIBUTION STATEMENT}

All authors contributed to the preparation of this manuscript. 


\section{REFERENCES}

1. Adams F. The extant works of Aretaeus: the Cappadocian (Sydenham Society, 1856).

2. Ansley L, Kippelen P, Dickinson J, Hull J. Misdiagnosis of exercise-induced bronchoconstriction in professional soccer players. Allergy, 67(3), 390-395 (2012).

3. Ansley L, Rae G, Hull JH. Practical approach to exercise-induced bronchoconstriction in athletes. Primary Care Respiratory Journal: Journal of the General Practice Airways Group, 22(1), 122-125 (2013).

4. Fitch KD. An overview of asthma and airway hyper-responsiveness in Olympic athletes. British journal of sports medicine, 46(6), 413-416 (2012).

5. Hull J, Ansley L, Garrod R, Dickinson JW. Exercise-induced bronchoconstriction in athletes-should we screen? Medicine and science in sports and exercise, 39(12), 2117 - 2124 (2007).

6. Parsons JP, Mastronarde JG. Exercise-Induced Bronchoconstriction in Athletes*. Chest, 128(6), 3966 (2005).

7. Price OJ, Ansley L, Menzies-Gow A, Cullinan P, Hull JH. Airway dysfunction in elite athletes-an occupational lung disease? Allergy, 68(11), 1343-1352 (2013).

8. Molphy J, Dickinson J, Hu J, Chester N, Whyte G. Prevalence of bronchoconstriction induced by eucapnic voluntary hyperpnoea in recreationally active individuals. $J$ Asthma, (2013).

9. Weiler JM, Bonini S, Coifman R et al. Work Group Report* American Academy of Allergy, Asthma \& Immunology Work Group Report: Exercise-induced asthma. The Journal of allergy and clinical immunology, 119(6), 1349-1358 (2007).

10. Parsons JP, Hallstrand TS, Mastronarde JG et al. An Official American Thoracic Society Clinical Practice Guideline: Exercise-induced Bronchoconstriction. American journal of respiratory and critical care medicine, 187(9), 1016-1027 (2013).

11. Bonini M, Lapucci G, Petrelli G et al. Predictive value of allergy and pulmonary function tests for the diagnosis of asthma in elite athletes. Allergy, 62(10), 1166-1170 (2007).

12. Rundell KW, IM J, Mayers LB, Wilber RL, Szmedra L, Schmitz HR. Self-reported symptoms and exercise-induced asthma in the elite athlete. Medicine \& Science in Sports \& Exercise, 33(2), 208 (2001).

13. Fitch KD, Sue-Chu M, Anderson SD et al. Asthma and the elite athlete: summary of the International Olympic Committee's consensus conference, Lausanne, Switzerland, January 22-24, 2008. Journal of allergy and clinical immunology, 122(2), 254-260. e257 (2008).

14. Godfrey S, Fitch KD. Exercise-induced Bronchoconstriction: Celebrating 50 Years. Immunology And Allergy Clinics of North America, (2013).

15. Anderson SD, Daviskas E. The mechanism of exercise-induced asthma is. Journal of allergy and clinical immunology, 106(3), 453-459 (2000). 
16. Anderson SD, Kippelen P. Airway injury as a mechanism for exercise-induced bronchoconstriction in elite athletes. Journal of allergy and clinical immunology, 122(2), 225-235 (2008).

17. Anderson S, Kippelen P. Exercise-induced bronchoconstriction: Pathogenesis. Current Allergy and Asthma Reports, 5(2), 116-122 (2005).

18. Hallstrand TS, Altemeier WA, Aitken ML, Henderson WR. Role of Cells and Mediators in Exercise-Induced Bronchoconstriction. Immunology And Allergy Clinics of North America, (2013).

19. Niinimaa V, Cole P, Mintz S, Shephard R. The switching point from nasal to oronasal breathing. Respiration Physiology, 42(1), 61-71 (1980).

20. Helenius IJ, Tikkanen HO, Haahtela T. Occurrence of exercise induced bronchospasm in elite runners: dependence on atopy and exposure to cold air and pollen. British journal of sports medicine, 32(2), 125-129 (1998).

21. Helenius IJ, Tikkanen HO, Sarna S, Haahtela T. Asthma and increased bronchial responsiveness in elite athletes: atopy and sport event as risk factors. Journal of allergy and clinical immunology, 101(5), 646-652 (1998).

22. Hallstrand TS. New Insights into to Pathogenesis of Exercise-induced Bronchoconstriction. Current Opinion in Allergy and Clinical Immunology, 12(1), 42 (2012).

23. Hallstrand TS, Moody MW, Wurfel MM, Schwartz LB, Henderson Jr WR, Aitken ML. Inflammatory basis of exercise-induced bronchoconstriction. American journal of respiratory and critical care medicine, 172(6), 679 (2005).

24. Mickleborough TD, Lindley MR, Ray S. Dietary salt, airway inflammation, and diffusion capacity in exercise-induced asthma. Med Sci Sports Exerc, 37(6), 904-914 (2005).

25. Mickleborough TD, Murray RL, Ionescu AA, Lindley MR. Fish oil supplementation reduces severity of exercise-induced bronchoconstriction in elite athletes. American journal of respiratory and critical care medicine, 168(10), 1181 (2003).

26. Hallstrand TS, Debley JS, Farin FM, Henderson Jr WR. Role of MUC5AC in the pathogenesis of exercise-induced bronchoconstriction. Journal of allergy and clinical immunology, 119(5), 1092-1098 (2007).

27. Bolger C, Tufvesson E, Anderson SD et al. Effect of inspired air conditions on exercise-induced bronchoconstriction and urinary CC16 levels in athletes. Journal of Applied Physiology, 111(4), 1059-1065 (2011).

28. Karjalainen E, Laitinen A, Sue-Chu M, Altraja A, Bjermer L, Laitinen LA. Evidence of airway inflammation and remodeling in ski athletes with and without bronchial hyperresponsiveness to methacholine. American journal of respiratory and critical care medicine, 161(6), 2086 (2000).

29. Kippelen P, Anderson SD. Airway injury during high-level exercise. British journal of sports medicine, 46(6), 385-390 (2012). 
30. Hull J, Hull P, Parsons J, Dickinson J, Ansley L. Approach to the diagnosis and management of suspected exercise-induced bronchoconstriction by primary care physicians. BMC Pulmonary Medicine, 9(1), 29 (2009).

31. Turcotte H, Langdeau J-B, Thibault G, Boulet L-P. Prevalence of respiratory symptoms in an athlete population. Respiratory medicine, 97(8), 955-963 (2003).

32. Langdeau J-B, Boulet L-P. Is asthma over-or under-diagnosed in athletes? Respiratory medicine, 97(2), 109-114 (2003).

33. Dickinson J, McConnell A, Whyte G. Diagnosis of exercise-induced bronchoconstriction: eucapnic voluntary hyperpnoea challenges identify previously undiagnosed elite athletes with exercise-induced bronchoconstriction. British journal of sports medicine, 45(14), 1126-1131 (2011).

34. Parsons JP, Kaeding C, Phillips G, Jarjoura D, Wadley G, Mastronarde JG. Prevalence of exercise-induced bronchospasm in a cohort of varsity college athletes. Medicine and science in sports and exercise, 39(9), 1487 (2007).

35. Hallstrand TS, Curtis JR, Koepsell TD et al. Effectiveness of screening examinations to detect unrecognized exercise-induced bronchoconstriction. The Journal of pediatrics, 141(3), 343-349 (2002).

36. Boulet LP. Asymptomatic airway hyperresponsiveness: A curiosity or an opportunity to prevent asthma? American journal of respiratory and critical care medicine, 167(3), 371 (2003).

37. Yoo Y, Choung JT, Yu J, Kim DK, Choi SH, Koh YY. Comparison of Percentage Fall in FVC at the Provocative Concentration of Methacholine Causing a 20\% Fall in FEV1 Between Patients With Asymptomatic Bronchial Hyperresponsiveness and Mild Asthma*. Chest, 132(1), 106-111 (2007).

38. Carlsen K, Anderson S, Bjermer L et al. Exercise-induced asthma, respiratory and allergic disorders in elite athletes: epidemiology, mechanisms and diagnosis: Part I of the report from the Joint Task Force of the European Respiratory Society (ERS) and the European Academy of Allergy and Clinical Immunology (EAACI) in cooperation with GA2LEN. Allergy, 63(4), 387-403 (2008).

39. Kujala UM, Sarna S, Kaprio J, Koskenvuo M. Asthma and other pulmonary diseases in former elite athletes. Thorax, 51(3), 288-292 (1996).

40. Becker JM, Rogers J, Rossini G, Mirchandani H, D'Alonzo Jr GE. Asthma deaths during sports: report of a 7-year experience. Journal of allergy and clinical immunology, 113(2), 264-267 (2004).

41. Amital H, Glikson M, Burstein M et al. Clinical Characteristics of Unexpected Death Among Young Enlisted Military PersonnelResults of a Three-Decade Retrospective Surveillance. CHEST Journal, 126(2), 528-533 (2004).

42. Abramson MJ, Walters J, Walters EH. Adverse Effects of $\beta$-Agonists. American Journal of Respiratory Medicine, 2(4), 287-297 (2003).

43. Bonini M, Di Mambro C, Calderon $\mathrm{M}$ et al. Asthma reliever inhalers (beta2-agonists) used for exercise-induced asthma and exercise-induced bronchoconstriction. Health, (2013). 
44. WADA. World Anti-Doping Agency. Medical Information to Support the Decisions of TUECS Asthma,http://www.wadaama.org/Documents/Science_Medicine/Medical_info_to_su pport_TUECs/WADA-Medical-info-Asthma-5.0-EN.pdf(Version 5.0) (2013).

45. Anderson S, Brusasco V, Haahtela T, Popov T. Criteria for diagnosis of asthma, EIB and AHR for athletes: lessons from the Olympic Games. EUROPEAN RESPIRATORY MONOGRAPH, 33, 48 (2005).

46. Anderson SD. Indirect Challenge TestsAirway Hyperresponsiveness in Asthma: Its Measurement and Clinical Significance. CHEST Journal, 138(2_suppl), 25S-30S (2010).

47. Crapo R, Casaburi R, Coates A et al. Guidelines for methacholine and exercise challenge testing-1999. This official statement of the American Thoracic Society was adopted by the ATS Board of Directors, July 1999. American journal of respiratory and critical care medicine, 161(1), 309 (2000).

48. Weiler JM, Anderson SD, Randolph C et al. Pathogenesis, prevalence, diagnosis, and management of exercise-induced bronchoconstriction: a practice parameter. Annals of Allergy, Asthma \& Immunology, 105(6), S1-S47 (2010).

49. Cockcroft DW. Direct Challenge TestsAirway Hyperresponsiveness in Asthma: Its Measurement and Clinical Significance. CHEST Journal, 138(2_suppl), 18S-24S (2010).

50. Rundell KW, Slee JB. Exercise and other indirect challenges to demonstrate asthma or exercise-induced bronchoconstriction in athletes. Journal of allergy and clinical immunology, 122(2), 238-246 (2008).

51. Anderson SD, Holzer K. Exercise-induced asthma: is it the right diagnosis in elite athletes? Journal of allergy and clinical immunology, 106(3), 419-428 (2000).

52. Porsbjerg C, Brannan JD. Alternatives to exercise challenge for the objective assessment of exercise-induced bronchospasm: Eucapnic voluntary hyperpnoea and the osmotic challenge tests. Breathe, 7, 52-63 (2010).

53. Dryden DM, Spooner CH, Stickland MK et al. Exercise-induced bronchoconstriction and asthma. Evidence Report/Technology Asssessment 189 (2010).

54. Sumino K, Sugar EA, Irvin CG et al. Methacholine challenge test: diagnostic characteristics in asthmatic patients receiving controller medications. Journal of allergy and clinical immunology, 130(1), 69-75. e66 (2012).

55. Bhagat R, Grunstein M. Comparison of responsiveness to methacholine, histamine, and exercise in subgroups of asthmatic children. The American review of respiratory disease, 129(2), 221-224 (1984).

56. Toelle B, Peat J, Salome C et al. Comparison of two epidemiological protocols for measuring airway responsiveness and allergic sensitivity in adults. European respiratory journal, 7(10), 1798-1804 (1994).

57. Juniper E, Frith P, Dunnett C, Cockcroft D, Hargreave F. Reproducibility and comparison of responses to inhaled histamine and methacholine. Thorax, 33(6), 705710 (1978). 
58. Chatham M, Bleecker E, Smith P, Rosenthal R, Mason P, Norman P. A comparison of histamine, methacholine, and exercise airway reactivity in normal and asthmatic subjects. The American review of respiratory disease, 126(2), 235 (1982).

59. Higgins B, Britton J, Chinn S et al. Comparison of histamine and methacholine for use in bronchial challenge tests in community studies. Thorax, 43(8), 605-610 (1988).

60. Anderson SD, Charlton B, Weiler JM et al. Comparison of mannitol and methacholine to predict exercise-induced bronchoconstriction and a clinical diagnosis of asthma. Respir Res, 10(4) (2009).

61. Cockcroft DW, Davis BE, Todd DC, Smycniuk AJ. Methacholine ChallengeComparison of Two Methods. CHEST Journal, 127(3), 839-844 (2005).

62. Ryan G, Dolovich M, Roberts $R$ et al. Standardization of inhalation provocation tests: two techniques of aerosol generation and inhalation compared. The American review of respiratory disease, 123(2), 195-199 (1981).

63. Todd DC, Davis BE, Hurst TS, Cockcroft DW. Dosimeter methacholine challenge: comparison of maximal versus submaximal inhalations. Journal of allergy and clinical immunology, 114(3), 517-519 (2004).

64. Allen ND, Davis BE, Hurst TS, Cockcroft DW. Difference Between Dosimeter and Tidal Breathing Methacholine ChallengeContributions of Dose and Deep Inspiration Bronchoprotection. CHEST Journal, 128(6), 4018-4023 (2005).

65. Cockcroft DW, Davis BE. The bronchoprotective effect of inhaling methacholine by using total lung capacity inspirations has a marked influence on the interpretation of the test result. Journal of allergy and clinical immunology, 117(6), 1244-1248 (2006).

66. Holzer K, Anderson SD, Douglass J. Exercise in elite summer athletes: challenges for diagnosis. Journal of allergy and clinical immunology, 110(3), 374-380 (2002).

67. Silverman M, Anderson SD. Standardization of exercise tests in asthmatic children. Archives of disease in childhood, 47(256), 882-889 (1972).

68. Rundell KW, Wilber RL, Szmedra L, Jenkinson DM, Mayers LB, Im J. Exerciseinduced asthma screening of elite athletes: field versus laboratory exercise challenge. Medicine and science in sports and exercise, 32(2), 309-316 (2000).

69. Anderson SD, Pearlman DS, Rundell KW et al. Reproducibility of the airway response to an exercise protocol standardized for intensity, duration, and inspired air conditions, in subjects with symptoms suggestive of asthma. Respir Res, 11, 120 (2010).

70. Eliasson A, Phillips Y, Rajagopal K, Howard R. Sensitivity and specificity of bronchial provocation testing. An evaluation of four techniques in exercise-induced bronchospasm. CHEST Journal, 102(2), 347-355 (1992).

71. Holzer K, Douglass J. Exercise induced bronchoconstriction in elite athletes: measuring the fall. Thorax, 61(2), 94-96 (2006).

72. Mannix ET, Manfredi F, Farber MO. A comparison of two challenge tests for identifying exercise-induced bronchospasm in figure skaters. CHEST Journal, 115(3), 649-653 (1999). 
73. Rundell KW, Anderson SD, Spiering BA, Judelson DA. Field exercise vs laboratory eucapnic voluntary hyperventilation to identify airway hyperresponsiveness in elite cold weather athletes. CHEST Journal, 125(3), 909-915 (2004).

74. Argyros GJ, Roach JM, Hurwitz KM, Eliasson AH, Phillips YY. Eucapnic voluntary hyperventilation as a bronchoprovocation technique. Chest, 109(6), 1520-1524 (1996).

75. Anderson S, Argyros G, Magnussen H, Holzer K. Provocation by eucapnic voluntary hyperpnoea to identify exercise induced bronchoconstriction. British journal of sports medicine, 35(5), 344-347 (2001).

76. Brummel NE, Mastronarde JG, Rittinger D, Philips G, Parsons JP. The clinical utility of eucapnic voluntary hyperventilation testing for the diagnosis of exercise-induced bronchospasm. Journal of Asthma, 46(7), 683-686 (2009).

77. Hurwitz KM, Argyros GJ, Roach JM, Eliasson AH, Phillips YY. Interpretation of eucapnic voluntary hyperventilation in the diagnosis of asthma. CHEST Journal, 108(5), 1240-1245 (1995).

78. Stadelmann K, Stensrud T, Carlsen KH. Respiratory symptoms and bronchial responsiveness in competitive swimmers. Medicine and science in sports and exercise, 43(3), 375-381 (2011).

79. Brannan J, Gulliksson M, Anderson S, Chew N, Kumlin M. Evidence of mast cell activation and leukotriene release after mannitol inhalation. European Respiratory Journal, 22(3), 491-496 (2003).

80. Brannan J, Gulliksson M, Anderson S, Chew N, Seale J, Kumlin M. Inhibition of mast cell PGD2 release protects against mannitol-induced airway narrowing. European Respiratory Journal, 27(5), 944-950 (2006).

81. Smith C, Anderson S. Inhalational challenge using hypertonic saline in asthmatic subjects: a comparison with responses to hyperpnoea, methacholine and water. European Respiratory Journal, 3(2), 144-151 (1990).

82. Brannan JD, Anderson SD, Perry CP, Freed-Martens R, Lassig AR, Charlton B. The safety and efficacy of inhaled dry powder mannitol as a bronchial provocation test for airway hyperresponsiveness: a phase 3 comparison study with hypertonic $(4.5 \%)$ saline. Respiratory research, 6(1), 144 (2005).

83. Riedler J, Reade T, Dalton M, Holst D, Robertson C. Hypertonic saline challenge in an epidemiologic survey of asthma in children. American journal of respiratory and critical care medicine, 150(6), 1632-1639 (1994).

84. Bonini M, Braido F, Baiardini I et al. AQUA: allergy questionnaire for athletes. Development and validation. Med Sci Sports Exerc, 41(5), 1034-1041 (2009).

85. Helenius IJ, Tikkanen HO, Haahtela T. Occurrence of exercise induced bronchospasm in elite runners: dependence on atopy and exposure to cold air and pollen. British journal of sports medicine, 32(2), 125 (1998).

86. Lee JH, Lee YW, Shin YS, Jung YH, Hong CS, Park JW. Exercise-induced airway obstruction in young asthmatics measured by impulse oscillometry. $J$ Investig Allergol Clin Immunol, 20(7), 575-581 (2010). 
87. Carvalhaes-Neto N, Lorino H, Gallinari C et al. Cognitive function and assessment of lung function in the elderly. American journal of respiratory and critical care medicine, 152(5), 1611-1615 (1995).

88. Zerah F, Lorino A-M, Lorino H, Harf A, Macquin-Mavier I. Forced oscillation technique vs spirometry to assess bronchodilatation in patients with asthma and COPD. CHEST Journal, 108(1), 41-47 (1995).

89. Vink GR, Arets HG, van der Laag J, van der Ent CK. Impulse oscillometry: a measure for airway obstruction. Pediatric pulmonology, 35(3), 214-219 (2003).

90. Buhr W, Jörres R, Berdel D, Làndsér FJ. Correspondence between forced oscillation and body plethysmography during bronchoprovocation with carbachol in children. Pediatric pulmonology, 8(4), 280-288 (1990).

91. Naji N, Keung E, Kane J, Watson RM, Killian KJ, Gauvreau GM. Comparison of changes in lung function measured by plethymography and IOS after bronchoprovocation. Respiratory medicine, (2013).

92. Rundell KW, Evans TM, Baumann JM, Kertesz MF. Lung function measured by impulse oscillometry and spirometry following eucapnic voluntary hyperventilation. Canadian respiratory journal, 12(5), 257-263 (2005).

93. Evans TM, Rundell KW, Beck KC, Levine AM, Baumann JM. Impulse oscillometry is sensitive to bronchoconstriction after eucapnic voluntary hyperventilation or exercise. Journal of Asthma, 43(1), 49-55 (2006).

94. Evans TM, Rundell KW, Beck KC, Levine AM, Baumann JM. Airway narrowing measured by spirometry and impulse oscillometry following room temperature and cold temperature exercise. CHEST Journal, 128(4), 2412-2419 (2005).

95. Carraro S, Corradi $\mathrm{M}$, Zanconato $\mathrm{S}$ et al. Exhaled breath condensate cysteinyl leukotrienes are increased in children with exercise-induced bronchoconstriction. Journal of allergy and clinical immunology, 115(4), 764-770 (2005).

96. Peroni DG, Chinellato I, Piazza $\mathrm{M}$ et al. Exhaled breath temperature and exercise-induced bronchoconstriction in asthmatic children. Pediatric pulmonology, 47(3), 240-244 (2012).

97. ElHalawani SM, Ly NT, Mahon RT, Amundson DE. Exhaled nitric oxide as a predictor of exercise-induced bronchoconstriction. CHEST Journal, 124(2), 639-643 (2003).

98. Barreto M, Zambardi R, Villa MP. Exhaled Nitric Oxide and other exhaled biomarkers in bronchial challenge with exercise in asthmatic children: current knowledge. Paediatric Respiratory Reviews, (2013).

99. Dweik RA, Boggs PB, Erzurum SC et al. An official ATS clinical practice guideline: interpretation of exhaled nitric oxide levels (FENO) for clinical applications. American journal of respiratory and critical care medicine, 184(5) (2012).

100. Feitosa L, Dornelas de Andrade A, Reinaux C, Britto M. Diagnostic accuracy of exhaled nitric oxide in exercise-induced bronchospasm: Systematic review. Revista Portuguesa de Pneumologia (English Edition), 18(4), 198-204 (2012). 
101. Hull JH, Ansley L, Robson-Ansley P, Parsons JP. Managing respiratory problems in athletes. Clinical Medicine, Journal of the Royal College of Physicians, 12(4), 351356 (2012).

102. Walsted NE, Hull JH, Backer V. High Prevalence of Exercise-Induced Laryngeal Obstruction in Athletes. Medicine and science in sports and exercise, (2013).

103. Rundell KW, Weiss P. Exercise-induced bronchoconstriction and vocal cord dysfunction: two sides of the same coin? Current sports medicine reports, 12(1), 4550 (2013).

104. Anderson SD, Brannan JD. Methods for "indirect" challenge tests including exercise, eucapnic voluntary hyperpnea, and hypertonic aerosols. Clinical reviews in allergy \& immunology, 24(1), 27-54 (2003).

105. Price OJ, Hull J, H. Asthma in elite athletes - who cares? . Clinical Pulmonary Medicine, In press (2013). 